\title{
Comments on "ICT Providers: A Relevant Topic for Business and Information Systems Engineering?"
}

DOI 10.1007/s12599-013-0256-6

\author{
The Author \\ Prof. Dr. Martin Kütz ( $\varangle)$ \\ Lehrgebiet Wirtschaftsinformatik \\ Fachbereich Informatik \\ und Sprachen \\ Hochschule Anhalt \\ Lohmannstr. 23 \\ 06366 Köthen (Anhalt) \\ Germany \\ m.kuetz@inf.hs-anhalt.de
}

Published online: 2013-02-22

This article is also available in German in print and via http://www. wirtschaftsinformatik.de: Kütz $M$ (2013) Kommentar zu „IKT-Anbieter als Thema der Wirtschaftsinformatik?". WIRTSCHAFTSINFORMATIK. doi: 10.1007/s11576-013-0356-4.

(C) Springer Fachmedien Wiesbaden 2013

„ICT providers: a relevant topic for business and information systems engineering?"(Hess et al. 2012) - What kind of a question is this! Would anyone think that the delivery of IT services is not a subject for business and information systems engineering (BISE)? If we study the support of business/economic activities by means of information processing and communication systems, then we cannot simply look at the demand side, but necessarily also at aspects of IT provision and IT governance. Whoever consumes resources has to take "make or buy" decisions. In the case of a buy-decision we cannot limit ourselves by viewing the procured product or service as "black box". In the interest of optimization, the complete supply chain must be studied and included in the decision. Obviously, not only the internal but also the external ICT providers are a fundamental subject of BISE.

But what if one would answer the question differently? I we would regard the cited CIO not as the top IT person but in fact as the top information manager who leads the information function of a business (or similar organization)? Who deals with information and not just with technology and systems? Who actually designs the information provision and dissemination processes of an organization, and not only provides a (technological) infrastructure? What remains would be a (fascinating) mixture of practical organization and information management. In this case, computer technology would be just an enabler and not the core subject. Admittedly, in business practice it could be wished to focus more on organization and information instead of immediately concentrating on platforms and systems. If we would dig into problems and once in a while try to creatively search for nontechnical solutions, and if we would not always try to get rid of all arising questions by employing massive IT applications. But would we, in this case, still talk about BISE? Would BISE be useful or even necessary as a discipline of its own? Probably not.

There is another reason why BISE is forced to deal with the production of ICT services and therefore with the producers of such services: it is not only about the application of ICT in the context of business activities but also about the efficiency of exactly such activities. Under which conditions does it make sense to use which ICT systems? "Sense" in this context means, not least, economic sense. Can the application be justified economically? If not BISE, who would think about the economic dimension of ICT? Therefore, BISE has to cover - last but not least - the accounting side of ICT. The scope is not limited to the efficiency of usage but also comprises the efficiency of provision. And whoever wants to assess the value of IT (to organizations) must necessarily evaluate the service creation. And - wanted or not - he must look at the creators of services and products.

I find it amazing that the topic has not been "discovered" before. But: better late than never. It's good if we (finally) add this aspect to our research spectrum. Our practitioner colleagues will appreciate it.

\section{References}

Hess T, Loos P, Buxmann P, Erek K, Frank U, Gallmann J, Gersch M, Zarnekow R, Zencke P (2012) ICT providers: a relevant topic for business and information systems engineering? Business \& Information Systems Engineering 4(6):367-373 